\title{
DETERMINATION OF BREAKAGE OF THE RUBBER STRIPS IN PLACES OF THEIR CONNECTIONS
}

Atakulov L.N. ${ }^{1}$, Gaffarov A.A. ${ }^{2}$, Khudoyberdiev L.N. ${ }^{3}$ (Republic of Uzbekistan) Email: Atakulov347@scientifictext.ru

\author{
${ }^{1}$ Atakulov Lazizjon Nematovich - Associate Professor PhD; \\ ${ }^{2}$ Gaffarov Azamat Alisherovich - Assistant; \\ ${ }^{3}$ Khudoyberdiev Lochin Nakovich - Assistant, \\ DEPARTMENT OF MINING ELECTROMECHANICS, \\ NAVOI STATE MINING INSTITUTE, \\ NAVOI, REPUBLIC OF UZBEKISTAN
}

\begin{abstract}
CPT-ore, which includes KNK-270, there are idle times. One of the main reasons for the downtime of the transport complex is the breakage of the rubber tape KNK-270. For this purpose, it is proposed to use the assembled flaw detector-tear detector. With the use of this equipment, the operational reliability of the KNK-270 is increased, the physical labor of the maintenance personnel is facilitated, the safety of work is increased, the material resources are saved from the purchase of additional tape sets and docking-adhesive materials.

Keywords: broken tape, docking points, tearing device, inductor, electromagnetic field, electrostatic plates, ammeter, oscillograph, automation, operational reliability.

\section{ОПРЕДЕЛЕНИЕ ОБРЫВА РЕЗИНОТРОСОВЫХ ЛЕНТ В МЕСТАХ ИХ} СТЫКОВКИ

\section{Атакулов Л.Н.1, Гаффаров А.А.ㄹ, Худойбердиев Л.Н. ${ }^{3}$ (Республика Узбекистан)}

\author{
${ }^{1}$ Атакулов Лазизжон Нематович - дочент, кандидат технических наук; \\ ${ }^{2}$ Гаффраров Азамат Алишерович - ассистент; \\ ${ }^{3}$ Худойбердиев Лочин Некович - ассистент, \\ кафедра горной электромеханики, \\ Навоийский государственный горный институт, \\ 2. Навои, Республика Узбекистан
}

\begin{abstract}
Аннотация: при эксплуатации транспортной линии ЦПТ-руда, в состав которой входит КНК-270, возникают простои. Одной из основных причин простоев транспортного комплекса является обрыв резинотросовой ленты КНК-270. Для снижения количества этих простоев и уменьшения материальных затрат, связанных с порчей ленты, необходимо своевременно и точно определять место обрыва. В этих иелях предлагается использовать собранный дефектоскоп-разрывоискатель. $C$ применением данного оборудования повышается эксплуатационная надежность КНК-270, облегчается физический труд обслуживающего персонала, растет безопасность работ, экономия материальных средств от приобретения дополнительных комплектов ленты и стыковочно-клеящих материалов.

Ключевые слова: обрыв ленты, места стыковки, разрывоискатель, катушка индуктивности, электромагнитное поле, электросталевые пластины, амперметр, осииллограф, автоматизаџия, эксплуатационная надежность.
\end{abstract}

В марте 2011 года на карьере «Мурунтау» Центрального рудоуправления Навоийского горнометаллургического комбината был произведен запуск в эксплуатацию уникального крутонаклонного конвейера КНК-270, который стал ключевым звеном в комплексе ЦПТ-руда (рис. 1). 


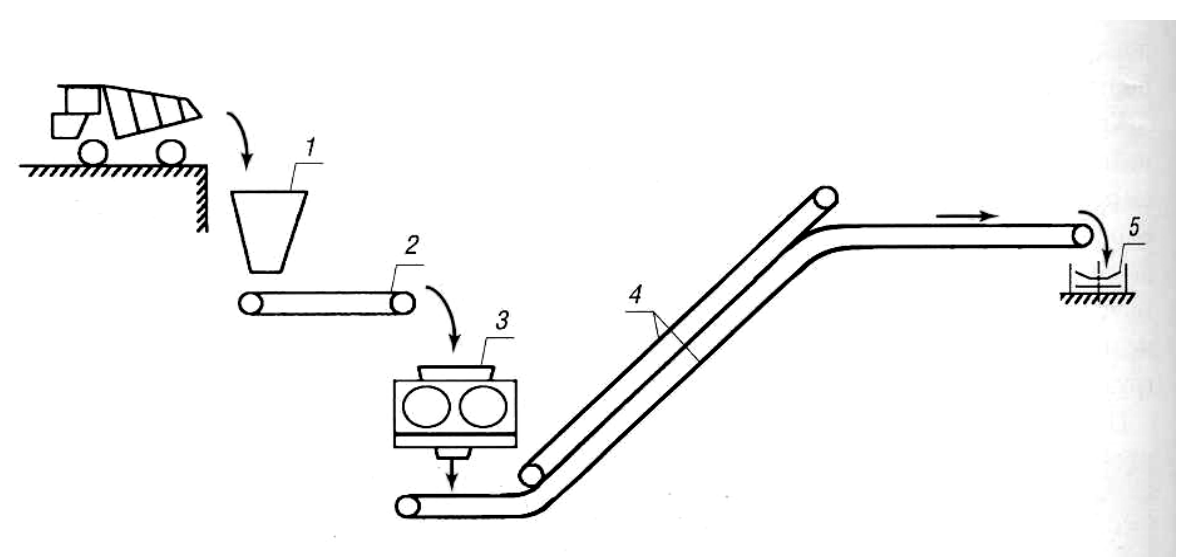

Рис. 1. Технологическая схема КНК - 270 в карьере «Мурунтау»:1-бункер, 2 -ленточный питатель, 3 - шнека зубчатая дробилка ДШЗ 1300/300, 4 - КНК - 270, 5 - складской конвейер

Потребность в создании крутонаклонного подъема возникла в связи с достижением запредельной (нерентабельной) для автотранспорта высоты подъема (более 500 м) и планами углубления карьера до 1000 м. Кроме того, из-за постоянные увеличения глубины дальнейшее развитие карьера было ограничено в связи с сокращением размеров горно-капитальных работ [2].

Выбор такого вида транспорта связан также с тем, что крутонаклонные конвейеры с прижимной лентой отличаются высокой универсальностью. Угол наклона может достигать $90^{\circ}$. Большое значение имеет тот факт, что конструкция крутонаклонного конвейера с прижимной лентой в большой степени унифицирована со стандартными ленточными конвейерами, хорошо зарекомендовавшими себя в условиях горных работ.

Как известно, КНК-270 эксплуатируемый в условиях карьера «М» ЦРУ НГМК является уникальной горнотранспортной машиной, об этом можно судить по её технической характеристике [1].

Но несмотря на уникальность конвейера, при его эксплуатации возникли проблемы, связанные с безотказностью и работоспособностью .

Частые простои транспортной линии с КНК-270 возникают в связи:

- с неисправностями электромеханического оборудования конвейеров и дробилок, входящих в состав комплекса ЦПТ-руда;

- с проведением долговременных проверок, настройки аппаратуры контроля и управления, устранения неполадок.

Так как основная часть простоев КНК-270 происходит по различным аварийным причинам, в связи с этим при расчете производительности конвейерных линий, необходимо более полно учитывать надежность комплектующего и вспомогательного оборудования.

Так, по статистике около 33\% простоев КНК-270 возникает из-за разрывов стыковочных мест на резинотросовой ленте (РТЛ) [4].

Для снижения количества этих простоев, уменьшения материальных затрат, связанных с порчей дорогостоящей ленты, необходимо своевременно и точно определять место обрыва.

В промышленности для решения подобных задач используют дефектоскопы - разрывоискатели (рис. 2.)

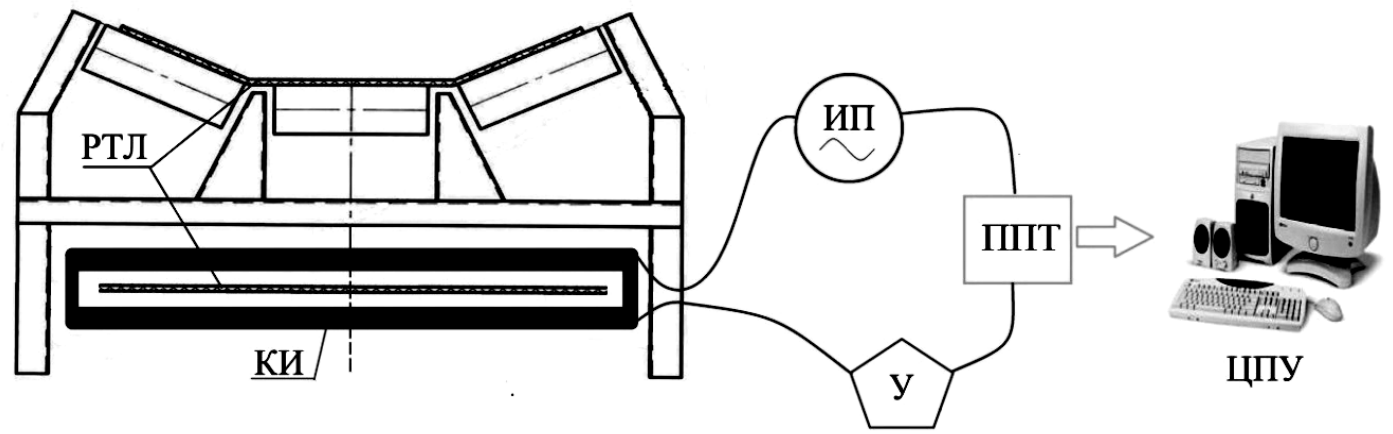

Рис. 2. Принципиальная схема работы дефектоскопа:

РТЛ - резинотросовая лента; КИ - катушка индуктивности; ИП - источник питания переменного тока; Уусилитель сигнала; ППТ - преобразователь переменного тока; ЦПУ - центральный пульт управления.

Принцип работы данных дефектоскопов:

При прохождении переменного электрического тока по катушке индуктивности (КИ), установленной на холостой (обратной) ветви конвейера вблизи концевого барабана, появляется электромагнитное поле, пересекающее 
трос РТЛ. Вариации электромагнитного поля, вызванные дефектами металлотросовой основы ленты, создают на выходе электрический ток, которых принимает вторая установочная установка.

Сигнал после улучшения усилителем (У) и преобразования в цифровую форму специальным прибором преобразователем переменного тока (ППТ) обрабатывается в микропроцессоре компьютера на центральном пульте управления (ЦПУ). В микропроцессор поступают также импульсы со счетчика метража (рук дел мастера программиста). Получаемая информация запоминается и выводится на монитор.

Для решения возникших проблем с КНК-270 преподавателями кафедры «Горная электромеханика» НГГИ, в настоящее время ведутся исследования. В связи с проведением экспериментов обрывов РТЛ собран специальный экспериментальный стенд (дефектоскоп-разрывоискатель), в котором через КИ с определенным количеством витков пропускается переменный ток определенного напряжения, силы и частоты (рис 3.). При прохождении элементов РТЛ через стенд, наблюдается изменение ее реактивного сопротивления.

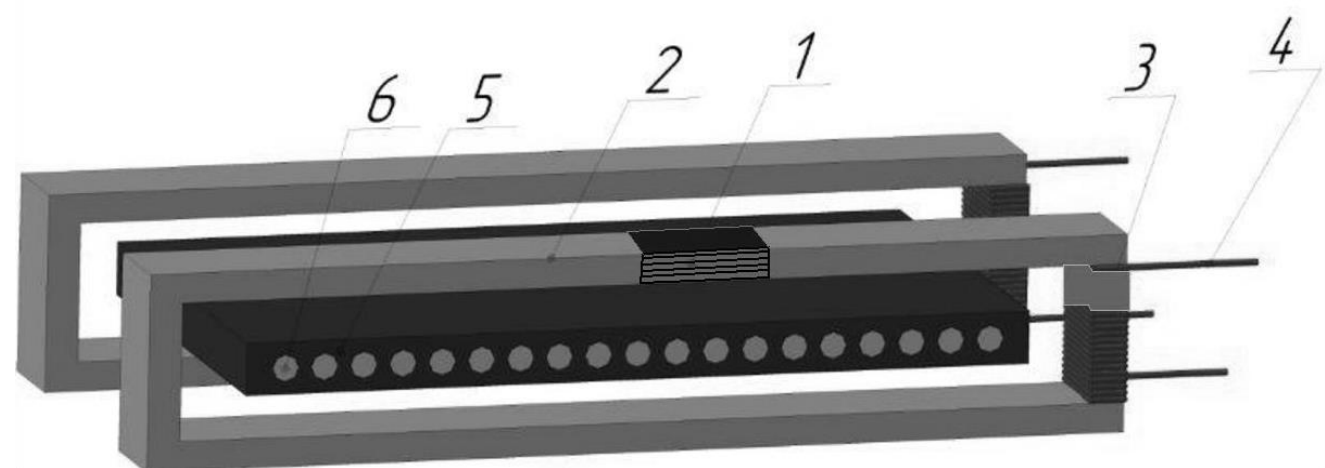

Рис. 3. Схема собранного дефектоскопа-разрывоискателя: 1 - электросталевые пластины (внутри корпуса), 2 корпус стенда, 3 - изолирующий материал, 4 - медная обмотка, 5 - резиностросовая лента, 6 - трос ленты

В комплект собранного дефектоскопа входит две установки, первая - создающая электромагнитное поле, вторая - принимающая сигнал магнитной индукции взаимодействия тросов с катушкой (рис. 3). Отличие схем собранных установок заключается лишь в толщине обмотки КИ и в количестве электросталевых пластин.

Измерительные приборы (амперметр, вольтметр, осциллограф, компьютер и д.р.) для считывания рабочих параметров подключаются к установке № 2 .

Для удобства проведения экспериментов, экземпляры РТЛ, марки St-5400 были располосованы на элементы длиной 3 м, с одно-тросовой; двух-; трёх-; до десяти-тросовой ленты.

Через магнитное поле КИ пропускали элементы РТЛ с одним, двумя и тремя тросами. В местах обрыва троса, показания прибора заметно менялись, причем полученные показания изменялись в зависимости алгебраической прогрессии (см. табл. 1).

Таблица 1. Результаты эксперимента (показания амперметра)

\begin{tabular}{|c|c|}
\hline Число тросов & Показания прибора мультиметра млА \\
\hline с 1 тросом & 3,2 \\
\hline с 2 тросами & 6,6 \\
\hline с 3 тросами & 10,1 \\
\hline с 4 тросами & 13,6 \\
\hline$\Delta$ & 3,4 \\
\hline
\end{tabular}




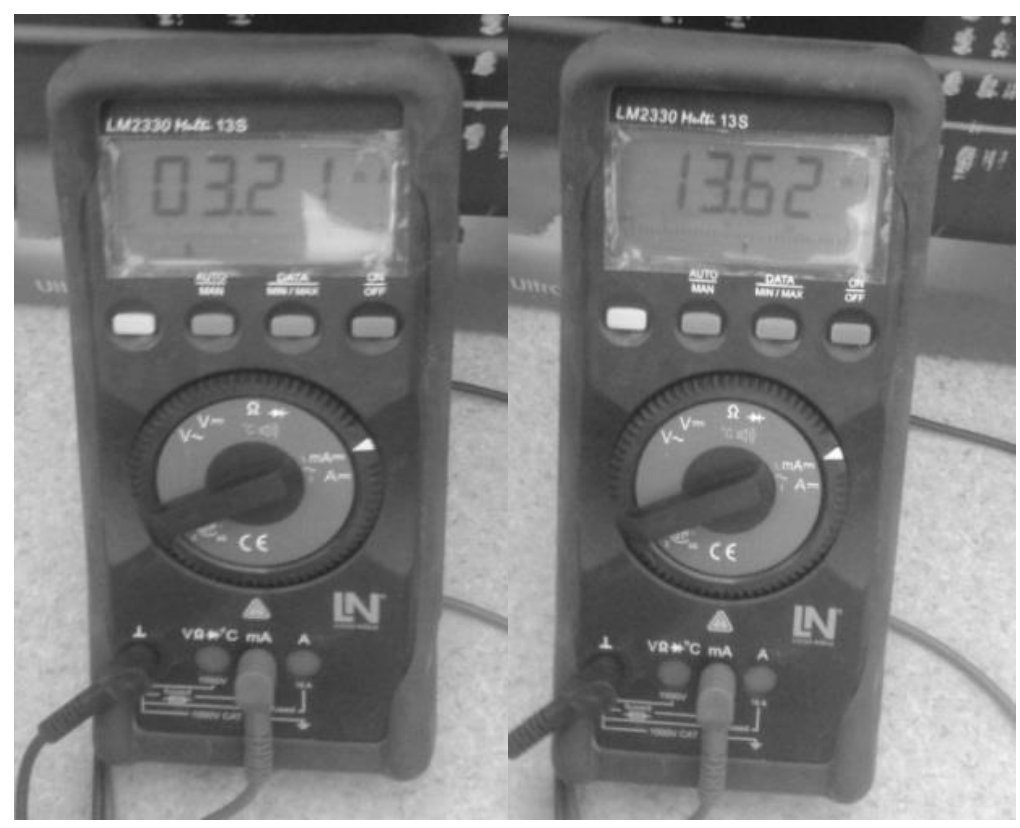

Рис. 5. Показание амперметра сизменением числа проходимых тросов РТЛ

Как видно из табл. №1, №2 и рис. 5 с изменением количества тросов РТЛ, проходимых через стендразрывоискатель, числовые показания амперметра менялись в алгебраической зависимости.

Получив цифровые значения в ходе экспериментов, (среднее показания одного троса - 3,4 млА) и зная общее количество тросов в РТЛ 2000St-5400 (114 шт.), можем подсчитать среднее значение сигнала по всему контуру ленты. Оно составит 365 млА. В случае резкого уменьшения фиксированных цифр означает разрыв РТЛ.

Разработанный дефектоскоп-разрывоискатель предлагается установить на холостой ветви КНК-270, около приводного барабана. Данные, считываемые с установок будут поступать на Центральный пульт управления ЦПТ, где в ON LINE режиме можно наблюдать за состоянием стыков РТЛ. Зависимость изменения определенного параметра тока от времени можно определить изменением параметров ленты от первоначального состояния (порыв, натяжение тросов и пр).

Дефектоскоп-разрывоискатель имеет целый ряд достоинств, таких как:

- возможность получения обширных данных о работоспособности РТЛ как в настоящее время, так и за прошедший период;

- обнаружение возникающих начальных моментов повреждения РТЛ в местах ее стыковки (обрывы, порывы, выход троса на поверхность);

- своевременная остановка конвейера при обрыве определенного количества тросов;

- малые затраты времени на ликвидацию неисправностей РЛТ, связанные с ремонтом поврежденного участка ленты (при своевременной подаче сигнала);

- простота управления и обслуживания оборудования;

- экономия денежных средств на закупку новой ленты и стыковочно-клеящих материалов.

Отличия между разработанным дефектоском-разрывоискателем и имеющихся зарубежных аналогов:

- предлагаемая модель имеет простую, но надежную рабочую схему;

- установка может быть собрана в условиях электромеханического цеха (участка);

- размеры корпуса, рабочее напряжение разрывоискателя могут варьироваться для конкретных условий эксплуатации конвейерных установок с РТЛ;

- монтаж дефектоскопа-разрывоискателя производится в короткие сроки, силами местного персонала (без привлечения зарубежных специалистов);

- необходимое оборудование, измерительные приборы, комплектующие детали и материалы не относятся к дифицитным и дорогостоящим, в связи с чем общая стоимость собранного дефектокопа составляет в несколько раз меньше зарубежных аналогов.

Таким образом, использование дефектоскопа-разрывоискателя позволит повысить эксплуатационную надежность КНК-270, облегчить физический труд обслуживающего персонала за счет автоматизации процесса, обеспечить безопасность работников при обслуживании КНК, сэкономить немалые денежные средства для предприятия от приобретения дополнительных комплектов РТЛ и стыковочно-клеящих материалов. 
1. Санакулов К.С., Шеметов П.А. Развитие циклично-поточной технологии в транспортной системе глубоких карьеров с применением крутонаклонных конвейеров. Журнал «О'zbekiston Konchilik xabarnomasi». № 2 (45), 2011. Стр. 140.

2. Кириченко А.Н., Картавый А.Н. Крутонаклонный конвейер КНК-270 для Навоийского ГМК - новый этап развития ЦПТ. Журнал «Горная промышленность». № 2 (90), 2010. Стр. 71.

3. Галкин В.В., Дмитриев В.Г., Дьяченко В.П., Запенин И.В., Шешко Е.Е. Современная теория ленточных конвейеров горных предприятий. М., МГГУ, 2005. 543 с.

4. Полунин В.Т., Гуленко Г.Н. Эксплуатация мощных конвейеров. М.: Недра, 1986. 